Revista LIDER, 37(22), 2020, pp. 100-115

eISSN: 0719-526

ISSN: 0717-0165

\title{
Construcción de territorio: elementos que ocultan memoria e identidad en el barrio Tucapel Bajo de Concepción
}

\section{Construction of territory: elements that conceal memory and identity in the Tucapel Bajo neighbourhood in Concepcion}

\section{Pablo Gaete Villegas}

Universidad de Concepción, Chile. pablo.gaeteville@gmail.com

\section{RESUMEN}

Este texto tiene como propósito aportar a la reflexión en torno al proceso de construcción social del territorio, con énfasis en los conceptos de memoria e identidad en contexto de pobreza urbana, a partir de la experiencia del barrio Tucapel Bajo en Concepción, Chile. En el análisis del proceso de construcción del territorio se analiza el concepto de espacio vivido, y de lugar antropológico acuñado por Marc Augé.

Palabras clave: espacio vivido; lugar; construcción de territorio; identidad y memoria

\section{ABSTRACT}

The purpose of this text is to contribute to the reflection on the process of construction of territory, emphasizing the concepts of memory and identity in a popular neighbourhood within an urban poverty context, starting from the experience of Tucapel Bajo neighbourhood in Concepción, Chile. These analyses of the process of construction of territory, are connected with the concept of "lived space", incorporating in this reflection the concept of "anthropologic place" coined by the French anthropologist Marc Augé.

Key words: lived space; place; construction of territory; identity and memory

Recibido: 28 de noviembre de 2018. Aceptado: 12 de mayo de 2020. 


\section{Lugar antropológico y espacio vivido}

El propósito de este trabajo es aportar a la reflexión en torno al proceso de construcción de territorio, poniendo énfasis en los conceptos de memoria e identidad en un barrio popular en contexto de pobreza urbana, exponiendo la experiencia del sector Tucapel Bajo de la ciudad de Concepción, Chile. Se estructura en dos acápites, problema de investigación, propuesta metodologica, hipotesis y las conclusiones. Se plantea el ejercicio de abordar el problema a la luz de los conceptos de lugar antropológico, acuñado por Augé (2000), y espacio vivido en el sentido que lo describen y aplican Aliste (2009) y Losada (2001).

El concepto espacio vivido tiene sus antecedentes en los trabajos pioneros de Henry Lefebvre (1974). Posteriormente, también lo han desarrollado otros autores en América Latina como Losada (2001) y Lerma (2013).

Es decir, se entregan elementos claves que forman una síntesis del relato correspondiente a una investigación sobre el proceso de construcción de territorio en el barrio Tucapel Bajo de Concepción, que indaga en el fenomeno del ocultamiento o ausencia de su memoria e identidad colectiva, en comparación con otros barrios populares y/o marginales de la ciudad de Concepción y que surgen en periodos y contextos sociopoliticos similares.

Como marco teórico de este estudio, se analizaron y pusieron en relación los conceptos de ciudad, barrio, lugar antropológico, periferia, marginalidad y espacio vivido a la luz de los estudios e investigaciones de los autores señalados. Para su construcción, se priorizó la comparación de los estudios y experiencias desarrolladas por las ciencias sociales, la geografía humana y el urbanismo, en diálogo crítico con estos autores desde la perspectiva latinoamericana, para la comprensión del fenómeno de la construcción social del territorio en Tucapel Bajo.

Los objetivos planteados dicen relación con identificar y describir los antecedentes históricos locales que dan origen al barrio, indagar en los fenómenos socioculturales que pudieron afectar la identidad barrial de los pobladores y reconocer elementos de memoria histórica local que hayan desaparecido o quedaron ocultos por nuevos referentes que asocian al barrio con los problemas de pobreza urbana y delinciencia juvenil.

\section{Identidad y memoria: ausencias en el barrio Tucapel Bajo}

\subsection{Caso de estudio}

El barrio Tucapel Bajo está emplazado en la periferia noroeste del casco urbano penquista y se conformó debido al flujo de la migración campo-ciudad a fines de la década de los cincuenta, instalándose provisoriamente en el sector denominado 
entonces como la Pampa, consolidándose luego como un campamento marginal luego del terremoto del año 1960, ampliandose a terrenos de propiedad municipal. Está asentado actualmente en un sector del humendal Paicaví, el que fue rellenado en parte por los propios pobladores durante años para la autoconstrucción de sus mediaguas. En 1992 se contruyó, por parte del Estado, la Villa Esperanza que reemplazó al antiguo campamento denominado "Condor Chileno". Es una comunidad actualmente muy estigmatizada por la delincuencia juvenil y el microtrafico de drogas. Los pobladores y pobladoras realizan trabajos precarios y viven toda la problemática asociada a la pobreza urbana y a la marginalidad social y territorial.

Figura 1. Plano de Concepción, 1895.

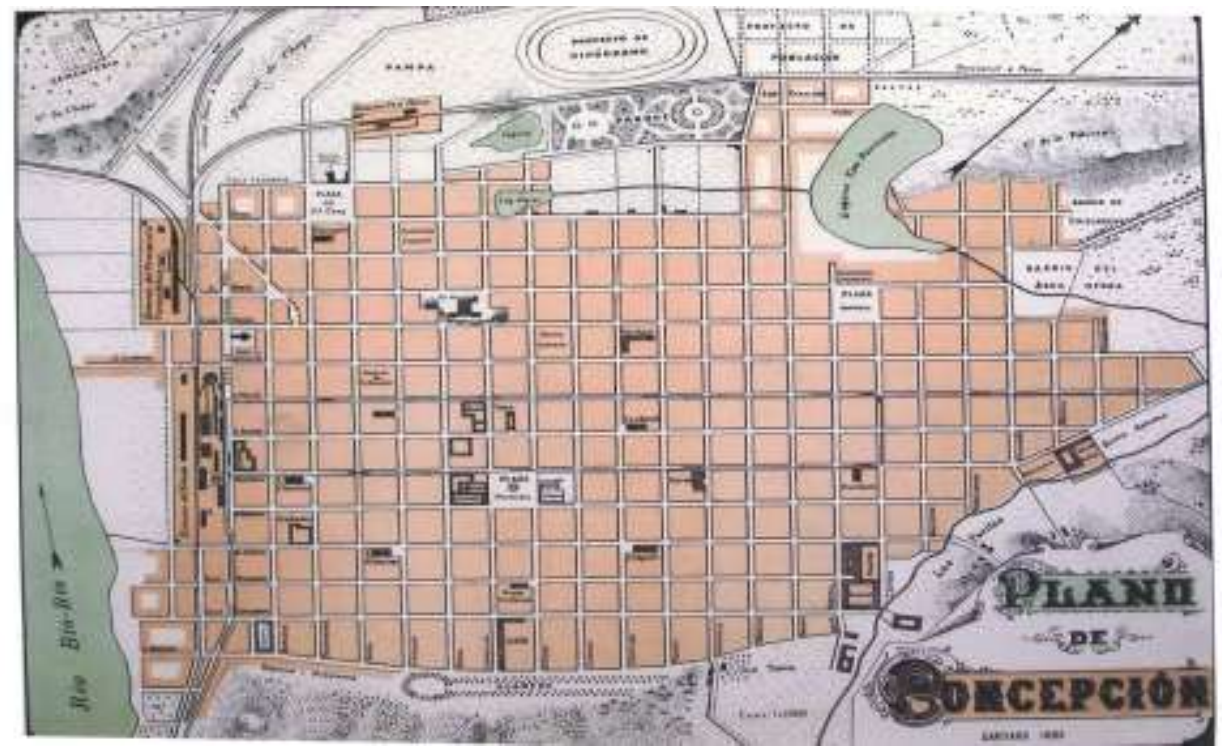

Fuente: Memoria Chilena (s.f.). Biblioteca Nacional. El sector señalado antiguamente como "Pampa" al oeste de la ciudad, es el lugar donde se emplaza hoy el barrio Tucapel Bajo.

\subsection{Problema de investigación}

En este punto tomaremos el concepto memoria en relación al territorio constituido por el barrio Tucapel Bajo de Concepción, problematizando el patrimonio en un contexto de marginalidad y pobreza urbana como resultado del proceso de modernización forzada que vivió nuestra sociedad a partir del golpe de Estado del año 1973.

Bruno Cárdenas (2005) describe al barrio como:

... espacio territorial, constituido simbólicamente por el hogar, el vecino y la vecindad, signos todos de valoración semántica positiva, significa el establecimiento de conexiones entre la familia y los demás, la sociedad próxima entre un yo y los otros y un nosotros y ellos mirados desde la amplitud barrial. Son estos espacios, desde los más inmediatos luego de franquear la 
puerta del hogar hasta los de mayor base territorial, en donde se generan lazos de identidad en relación con los demás miembros del colectivo. En consecuencia, el espacio es determinante por cuanto constituye el territorio del enraizar, de echar o criar raíces, de manera que en cada instante que el sujeto regresa está reactualizando y resignificando el valor de pertenencia con sus usos y costumbres (p. 100).

Si se compara al barrio de Tucapel Bajo con otros sectores de Concepción como el de Agüita de la Perdiz o Aurora de Chile, se observa que estos últimos, a pesar de la marginalidad social y urbana que sufren, tienen y evidencian elementos identitarios y de reconocimiento de su propia memoria. Incluso en algunos de ellos se observa un sentido de ser sujetos populares con sentido histórico ${ }^{1}$.

Por otro lado, los pobladores del barrio Aurora de Chile, se identifican asimismos como pioneros, destacando su temprana llegada a la costanera fluvial de Concepción y la proeza de quitar terreno al río Biobío para construir sus precarias viviendas a principios del siglo XX. En los ultimos años, reportajes peridisticos e investigaciones académicas dan cuenta de ello.

Traían escombros del centro, de las construcciones, en carretones con caballos. Entonces siendo niños de pantalón corto y a patita pelada salíamos a pedir a los carretoneros que venían a botar escombros que por favor que los trajera acá (...) Ahí, con los demás chiquillos de los vecinos, todos, porque todos nos ayudábamos, empezábamos con las 21 palas a tirar, descargando el camión (...) No había baño, no había alcantarillado, no había agua potable, no había nada. Así fuimos creciendo y así fuimos ganándole al río. Poco a poco (poblador/a sector Costanera (Cabrera y Lasalle 2000, citado en Saldía, 2018, p. 17).

En cambio, Tucapel Bajo no presenta evidencia alguna o señal visible de reconocimiento social o referencia simbólica de su memoria. Actualmente el estigma de barrio asociado a problemas tan graves derivados de la pobreza urbana como la delincuencia juvenil y el microtráfico de droga, parecieran haber borrado o anulado cualquier expresión de identidad y memoria barrial en los pobladores que actualmente viven allí. Esto se expresa cuando han demostrado que a la primera posibilidad de cambiarse de barrio no dudan en hacerlo, o bien cuando buscan separarse del estigma afirmando el nombre de la Villa Esperanza para diferenciarlo

${ }^{1} \mathrm{Al}$ respecto se han escrito libros que describen el proceso de construcción identitaria y el rol de los dirigentes en ese proceso en el caso del barrio Agüita de la Perdiz . En textos como "Aguita de la Perdiz, Vidas Combativas" de Nelson Alvarez (2011) y "Cuentos y Personajes de la Aguita de la Perdiz" de Víctor Ferreira y otros autores (2012), esto queda en evidencia. 
del sector Tucapel Bajo, que tiene una fuerte connotación negativa para los pobladores

A pesar de todo lo que se estigmatiza el lugar, es un amor tan grande que uno le tiene al lugar. El hecho de haber pasado todos estos años, todas estas cosas, que han ido evidenciando que ha mejorado realmente de cómo nosotros vivíamos antes; y ahora, es maravilloso... mis hijos dicen "yo quiero emigrar de acá”, pero es algo que uno tiene sus raíces y sus recuerdos de su familia...dentro de todo sin tristeza, porque hay muchos que ya no están de nuestros seres queridos que vivimos aquí (Entrevista ex Presidenta de la Junta de Vecinos).

Para definir el problema, surgen varias interrogantes. ¿Porqué, si otros barrios de la ciudad de Concepción, como los mencionados en el punto anterior, tuvieron un origen y desarrollo similar y también fueron afectados por los mismos factores del modelo neoliberal en su efectos excluyentes y de extrema segmentación social y espacial, aún mantienen cierto rasgos identitarios y de reconocimiento de su memoria colectiva, éstos aspectos no se observan en Tucapel Bajo? ¿Es posible que factores tan comunes en contexto de pobreza urbana como la delincuencia juvenil y el microtráfico de drogas hayan borrado los elementos identitarios y de memoria en el barrio? ¿Cómo podemos afirmar que existieron efectivamente estos elementos de identidad con el territorio? ¿Qué registros existirán aun respecto al surgimiento del barrio y su imaginario? ¿Cuál será la descripción que las familias hacen del territorio de la antigua toma que dio origen a la población? Finalmente, ¿habrá elementos que los propios pobladores puedan reconocer como "patrimoniales" en el barrio de Tucapel Bajo?

Si se entra desde calle Colo Colo se camina en una calle de tierra, sin pavimento, con sitios eriazos. Allí todavía se ven transitar carretones tirados por caballos, que son capital de trabajo de los feriantes y al mismo tiempo prestan servicios de transporte a los vecinos de la comunidad. Los pasajes son angostos y la trama nos es cuadricula como las cuadras del centro. Las casas son bajas, algunas de techo plano y de material ligero. Todavía hay un canal de aguas detenidas con mucha vegetación natural. Este viejo pantano se niega a morir a pesar de todos los rellenos y construcciones cercanas, este mismo lugar hoy es reconocido como un humedal. Este lugar da la sensación de estar viviendo una realidad particular, un paisaje típico de los años sesenta, cuando recién se conformaron las poblaciones callampas, denominación chilena a los campamentos de viviendas precarias que se levantaban en "tomas" de terreno en la periferia, igual que en muchas de las grandes ciudades de América Latina durante la migración campo-ciudad de la década de los 50 y 60 del siglo pasado. En el caso de Concepción las tomas de terreno se efectuaron principalmente en sitios baldíos (humedales) y alrededor de las lagunas del sector norte y en las orillas del río Biobío y del Andalién. 
Para desentrañar los procesos de construcción del territorio conocido como barrio Tucapel Bajo de la ciudad de Concepión, se desarrolló un estudio de campo con un enfoque cualitativo, etnográfico e histórico; y una investigación de antecedentes en la prensa y archivos de instituciones locales, lo que implicó realizar catastros de organizaciones e instituciones que guardan memoria del territorio. (Identificación y registro de sus ámbitos de acción). Entrevistas semiestructuradas y focus groups con dirigentes comunitarios, líderes e informantes claves del barrio, organizaciones, como el club deportivo, centro de madres, los grupos católicos asociados a la capilla y pastores de iglesias evangélicas. Aplicación de encuestas a los vecinos para conocer el grado de identificación o arraigo con el barrio y analizar posibles elementos de construcción patrimonial con la memoria histórica del barrio desde la perspectiva de los propios pobladores. Y se hizo una sistematización y análisis de la información recolectada para procesarla de acuerdo a la problemática levantada como investigación de campo barrial.

Fundamentado en lo anterior, proponemos como hipótesis una ausencia de memoria, o la existencia de memoria oculta del barrio. El resultado es que ha quedado pendiente la construcción de territorio y no se ha consolidado una comunidad con espacio vivido, resaltando débiles lazos identitarios, suspendiendose el paso a la modernidad que se distinguen mientras uno se adentra en el territorio, divisado como una realidad distinta del entorno.

Siguiendo el concepto de espacio vivido de Enrique Aliste (2011), que propone otras lecturas posibles, considerando que "desde la perspectiva de los imaginarios del desarrollo, surge la oportunidad de visualizar estas ciudades ocultas, (o barrios populares marginales, podemos agregar), aquel reflejo ineluctable de la experiencia de habitar un espacio que es cargado de sentido desde los diferentes procesos sociales que le otorgan sentido" (p. 25).

En este caso, es probable que los pobladores originarios de Tucapel Bajo no hicieran propio este espacio, es decir no alcanzaran a construir totalmente su territorio. $\mathrm{Y}$ este proceso incompleto no haya alcanzado a fortalecer las redes de solidaridad entre los integrantes de esa comunidad, afectando el reconocimiento de elementos comunes de identificación barrial.

Esto último se ha visto reafirmado con los testimonios recogidos a dos antiguos dirigentes del barrio, quienes coinciden en reconocer que el origen fundacional del barrio, no fue una ocupación tipo toma de terreno como se gestaron distintas poblaciones populares en la periferia de las ciudades durante la década de los sesenta, sino que fue la coyuntura post-terremoto del 60, lo que llevó a varias familias de pobladores a arrendar terrenos que eran de propiedad municipal para construir viviendas de emergencia. 
$\mathrm{Al}$ respecto, es enfático el principal dirigente de la población, don Patricio Torres, quien lideró el proceso para la construcción de la población Villa Esperanza desde fines de la década del setenta. Evitando una probable erradicación, se organizaron por primera vez en una Junta de Vecinos, dando inicio a un período en que la comunidad se mantuvo unida con el claro objetivo de no aceptar el traslado y, gestionar ante las autoridades de la época la construcción de sus propias viviendas. Recordando los orígenes de la comunidad señala “...no, esto nunca fue toma. Siempre fue con autorización de la municipalidad, y se pagaba un arriendo. Eso nunca fue un terreno malo, había vegas, donde se sembraba" (Entrevista Ex Presidente de la JJ.VV.).

Terrenos que se ocuparon para cultivos de hortalizas y que fueron perdiendo valor que en ese tiempo recibían el nombre genérico de "la Pampa":

Estos eran terrenos de propiedad municipal, y después del terremoto del año 1960, dieron la posibilidad de construir casas a algunas familias mediante el pago de un derecho a uso del suelo. Todos estos terrenos eran "chacras" y hortalizas que cultivaban algunos funcionarios de la Municipalidad, y más allá estaban los terrenos de un señor italiano llamado Bonifacio Falcone (Testimonio ex dirigente).

Como se señala en el punto anterior, nuestra hipótesis se plantea sobre la comparación con la experiencia y procesos vividos por otros barrios populares de Concepción, que surgieron en períodos históricos similares en el contexto de la migración campo-ciudad de los años cincuenta y sesenta del siglo pasado. Se plantea que la falta de una épica en el hito fundacional del barrio coadyuvó a debilitar la construcción de memoria e identidad entre estos pobladores. Aspectos que se fueron debilitando aún más como producto de la modernización forzada que impuso el modelo neoliberal, olvidando el sentido originario de comunidad, ocultando las redes de confianza que les permitieron organizarse para luchar por la construcción de sus viviendas. Hoy, sólo son visibles los problemasque estigmatizan a los pobladores: delincuencia juvenil, microtráfico, violencia intrafamiliar y trabajo precario.

Pero la pregunta sigue pendiente: ¿dónde está el patrimonio en Tucapel Bajo de Concepción? Si consideramos que el "patrimonio es una práctica cultural dinámica, donde se ponen en juego valores sociales" (De Nordenflycht, 2013), no sería extraño que esta falta de visibilidad de elementos de memoria común en los pobladores aflore rápidamente cuando se les invite a re-visitar sus propias historias familiares, a resignificar su rol como pobladores que, al igual que otros sectores sociales, han sido parte de la construcción de este gran espacio urbano, hoy llamado el Gran Concepción. Se descubre así, en su practica cultural dinámica, una narrativa reconocida como fundante de la población o algún sitio que tenga para ellos 
alguna carga simbólica; elementos que los propios pobladores logran distinguir como patrimoniales.

\section{3. ¿Es el territorio de Tucapel Bajo un lugar antropológico o un espacio vivido?}

\subsection{El lugar antropológico}

Dice Augé (2000) que "estos lugares tienen por lo menos tres rasgos comunes. Se consideran (o los consideran) identificatorios, relacionales e históricos” (p. 58). Es decir, que los grupos humanos tienen la necesidad de poseer una identidad y por lo tanto crear símbolos que sean compartidos por el conjunto del grupo, y de quienes se vayan integrando al colectivo, en este caso, los pobladores de Tucapel Bajo. Al mismo tiempo, requieren establecer una relación entre la identidad que es compartida y aceptada por el grupo y las identidades particulares de cada individuo. Un aspecto importante en la construcción de la identidad es para este autor el lugar de nacimiento, sobre ello explica que "nacer es nacer en un lugar, tener destinado un sitio de residencia. En este sentido el lugar de nacimiento es constitutivo de la identidad individual" (Augé, 2000, p. 59).

Si bien hay que considerar que los pobladores y las primeras familias que formaron el barrio llegaron a "vivir" en al territorio de Tucapel Bajo, todas las generaciones posteriores nacieron allí, se criaron allí y estudiaron en su mayoría en la escuela del barrio, la Escuela Básica D-555, ubicada en calle Ejército, hoy desaparecida por falta de matrícula como tantos otros establecimientos de educación municipal.

Augé (2000) dice que para que un lugar sea antropológico, debe estar presente el aspecto de las relaciones. Citando a Michel de Certeau, señala que en cualquier lugar existe un orden según el cual los elementos son distribuidos en sus relaciones de coexistencia. Con ello quiere decir que en un mismo lugar pueden habitar elementos diversos y particulares como es evidente, pero que esto no es impedimento para que se establezcan relaciones y se construyan identidades comunes a todos los habitantes de un mismo lugar.

Aunque parezca obvio, en el territorio de este estudio, los pobladores articulan relaciones de diversa índole, siendo las más básicas, las familiares, las inter-familiares y las vecinales. Las relaciones se van haciendo más complejas cuando éstas se establecen bajo las formalidad de una organización ya sea de carácter religioso (la capilla de los católicos y la Iglesia evangélica), deportivo (Club de Fútbol El Pampa) o de desarrollo vecinal, como la junta de vecinos de Villa Esperanza y la Junta de Vecinos de Tucapel Bajo. Todo esto implica reconocer liderazgos, elegir dirigentes, 
en algunos casos y, en otros, establecer ciertas normas o fijarse objetivos comunes según la naturaleza de cada organización.

Junto a la identidad, y las relaciones de la comunidad, Augé considera que un lugar antropológico debe tener sentido histórico, es decir debe contar con una trayectoria en el tiempo. En ese lugar existen ciertos hitos que sólo quienes viven ahí los reconocen, tienen un historia común. En palabras de Augé (2000), "el habitante del lugar antropológico vive en la historia, no hace historia" (p. 60).

Luego de este breve análisis de algunas de las ideas de Marc Augé, volvamos a la pregunta inicial ¿Es Tucapel Bajo un lugar antropológico? ¿Se cumplen las tres características que el autor reconoce como partes integrantes de este concepto? En el sector de Tucapel bajo, podemos hasta ahora reconocer la existencia de relaciones de distinto tipo entre sus habitantes y el territorio. También se observa que la comunidad posee una historia que todos recuerdan o reconocen. Los vecinos más antiguos, relatan los orígenes del poblamiento del territorio y los más jóvenes recuerdan la construcción de las viviendas de Villa Esperanza a principios del los años noventa como hito importante. Pero ¿̇cuál es la identidad de los vecinos, cual es la identidad del barrio? O ¿cuáles son los elementos que identifican al barrio y que sus habitantes reconocen como tales? Esto es precisamente lo que no es aún claramente visible, lo que permanece oculto y es el problema de la investigación que aquí se busca responder.

\subsection{Espacio vivido en el territorio de Tucapel Bajo}

Lo anterior está ligado a otro concepto que nos ayuda al análisis del problema. Este es el concepto de espacio vivido, que si bien tiene antecedentes en los primeros estudios de Lefebvre (1974), ha sido desarrollado por otros autores. En esta oportunidad tomaremos el enfoque que la investigadora Flora Losada (2001) y el geógrafo Enrique Aliste (2011) aplican en sus estudios. Ellos definen el proceso como uno en que los habitantes de un espacio se apropian de él y lo transforman en territorio, "el territorio es el resultado de un complejo proceso de apropiación del espacio. Uno de los elementos que permite entender el cómo este espacio se comienza a hacer propio por quienes habitan y viven estos territorios, es el concepto de espacio vivido" (Aliste, 2011, p. 25).

En primer lugar, indaguemos la noción espacio vivido. Todos constatamos que las acciones e interrelaciones de los individuos o grupos humanos suceden en un espacio determinado. Aunque éste no determine el comportamiento de quienes lo habitan; los flujos, reflujos y líneas de fuga que se producen cotidianamente, en la interacción con el espacio si se genera una significación para los que allí viven. Es más, en el lenguaje coloquial, cuando se le pregunta a una persona por su residencia responde "yo vivo en tal parte". O sea, existo en ese espacio. Según Losada (2001) 
El espacio, percibido por medio de todos los sentidos, adquiere una determinada significación para quienes viven inmersos en él; la cual deviene de la experiencia continua y cotidiana de la vida que allí tiene lugar. Experiencia que abarca no sólo a las actividades que una persona puede desarrollar individualmente sino, principalmente, a toda la gama de interacciones sociales utilizadas por el individuo (p. 271).

Si este proceso complejo de apropiación del espacio, como dice Aliste (2009), lo desarrollaron en el tiempo los vecinos de Tucapel Bajo, entonces estamos en presencia de un territorio. Pero la pregunta para nosotros es ¿cómo comenzaron a hacer propio este espacio los pobladores? y ¿qué complejos procesos se sucedieron en ese intertanto?

Aquí conectamos con las preguntas fundamentales de nuestro problema: ¿existe memoria colectiva entre los pobladores de Tucapel Bajo o está oculta bajo las duras experiencias que muchos territorios de pobreza urbana debieron vivir bajo la modernización forzada que vivió nuestro país a partir de septiembre de 1973? Y si no hay memoria, ¿dónde está el patrimonio en este barrio popular y estigmatizado por la delincuencia juvenil y el micrográfico de droga?

Buscando respuestas seguimos apelando al concepto de espacio vivido, según Losada (2001) cuando explica que:

Esta significación se elabora/reelabora día a día en virtud de una experiencia individual y social con el espacio en que se desarrolla el comportamiento y se halla condicionada por factores tales como la cultura, la pertenencia a una clase o grupo social, los conocimientos adquiridos por los individuos, el lugar de origen, sus historias de vida, entre otras variables (p. 175).

\subsection{Barrios populares y patrimonio}

Quizá en este punto es necesario hacer un distingo. A la fecha se han realizado estudios sobre memoria e incluso investigaciones históricas de barrios patrimonializados que cuentan con una carga simbólica en el imaginario nacional, como por ejemplo el barrio Yungay de Santiago o el barrio La matriz de Valparaíso. Estos barrios tienen un origen distinto del punto de vista de la composición social de sus habitantes, de la funcionalidad urbana y del valor económico del territorio. Son espacios de con-vivencia comunitaria asociados fuertemente a su propia historia y a la relación del barrio con la historia de la ciudad o del país. Tucapel Bajo de Concepción, en cambio, es un barrio que surge en otro contexto y bajo otras condiciones históricas y políticas.

El relato histórico de este proceso (Migración campo-ciudad 1885-1952), señala que los barrios populares que se establecieron en la periferia de Concepción, al igual que en otras ciudades de Chile y de América Latina, se explican por un flujo 
potente, un flujo migratorio campo-ciudad que atrae al mundo campesino a instalarse en los suburbios de las grandes ciudades en busca de lo que trae consigo la vida moderna: trabajo asalariado en las industrias emergentes, en los centros mineros, educación para sus hijos, mejores niveles sanitarios. Y por supuesto, también se cruzan los factores anteriores con los atractivos simbólicos de la ciudad: entretención nocturna (prostíbulos), adquisición de aparatos tecnológicos modernos (radio, victrolas, tocadiscos), medios de comunicación, la sociabilidad. Pero en el caso de Concepción, podemos agregar otros factores que nos ayudan a comprender la existencia de estos barrios marginales ubicados en la periferia de la ciudad, entre los que distinguimos Tucapel Bajo.

Con la creación de la CORFO y la llamada política de sustitución de importaciones que el Estado chileno impulsó luego del terremoto del 39 durante el siglo pasado, se generó una fuerte industrialización en la zona con la instalación de la usina de Huachipato en Talcahuano, las textiles en Tomé, la refinería de azúcar CRAV y Fanaloza en Penco, Vidrios en Lirquén y la Refinería de petróleo en San Vicente. Sumado todo esto a la antigua explotación del carbón en Lota, Coronel y la provincia de Arauco, generó una gran demanda de mano de obra que fue suplida rápidamente por campesinos jóvenes que, desde el Maule por el norte y la Araucanía por el sur, llegaban en masa en busca de trabajo y mejores condiciones de vida a la ciudad. Junto con esto y también como efecto del mismo terremoto del año 39 que destruyó Chillán y afectó fuertemente a Concepción, se eliminaron los conventillos del centro de la ciudad y con ello se aceleró la creación de asentamientos precarios en los suburbios (Pacheco, 1997).

En una perspectiva más teorica, es muy clarificador el texto "Lo Común y lo Colectivo" de Manuel Delgado (2011) cuando plantea, respecto a la "comunidad perdida", el efecto devastador que tuvo el capitalismo en sus orígenes sobre sociedades basadas en las redes de confianza del parentesco familiar, la vecindad y la convivencia en un territorio común. Al distinguir "comunidad" de "colectivo" en el mismo texto, Delgado cita al autor Maurice Halbwachs quien señala que "esa idea de lo común hace que la comunidad que de ella se deriva se presente como unidad social severamente jerarquizada, que encierre a sus componentes en un orden cosmovisional y organizativo del que ni deben ni sabrían escapar". Por su parte lo colectivo "se asocia con la idea de reunión de individuos que toman consciencia de lo conveniente de su copresencia y la asumen como medio para obtener un fin, que puede ser el de simplemente sobrevivir" (Delgado, 2011, p. 6). 


\section{Conclusiones}

Una primera constatación es que, para la comunidad de Tucapel Bajo, la obtención de la vivienda propia con la construcción de la población a principios de los 90 tuvo un cierto significado de carácter épico, que puede asociarse a la idea colectiva de un proceso fundante del nuevo barrio como lo conocemos actualmente (Villa Esperanza).

Nosotros llegamos el año 1957, cuando había 5 casas aquí en este sector. Antes tenía un cierre Tucapel, con un portón y un candado. La señora que nos dio la pasada por abajo fue la Sra. Panchita. Yo tenía unos 14, 15 años más o menos (Entrevista a ex dirigente de la primera organización vecinal del barrio).

Si bien nuestra hipótesis de la ausencia de una gesta o hito épico en la fundación de la comunidad se confirma de acuerdo a lo mencionado por los entrevistados, al mismo tiempo la investigación revela una épica en el proceso, en la gestión de alcanzar la meta de la vivienda propia luego de 30 años de vivir en pobreza y marginalidad sin las condiciones básicas de habitabilidad.

Entonces, ¿Qué más iban a querer? No querían nada más que cerrar la puerta de su casa y decir "ahora soy feliz". Yo le digo, la gente estaba tan tremendamente contenta y emocionada, porque era su cocina, su espacio, dormitorios, donde poner un living; son viviendas pequeñas, pero para ellos era maravilloso. Entonces, cuando está resuelto el objetivo por el que se formaron, por el que lucharon, ¿qué más que cerrar las puertas y decir "ahora nada más”? (Entrevista a Asistente Social, Municipalidad de Concepción).

Estas primeras referencias dan cuenta del logro del objetivo general que nos planteamos para esta investigación, en el sentido de identificar y caracterizar elementos de memoria e identidad en los pobladores. Cada entrevistado fue reconociendo las prácticas sociales de la comunidad y cómo fueron construyendo su territorio en la vivencia cotidiana y en la organización vecinal que les permitió mejorar sus condiciones de vida, al pasar del campamento a la villa. La conclusión es que este tipo de procesos pueden derivar en hitos identitarios, que hoy permiten ser recogidos como patrimonio en el sentido histórico, valórico y social.

Bueno, antes cuando nos entregaron la población nueva, ahí se hacía el aniversario todos los años. Los pasajes se adornaban para el 18, para la pascua. Los vecinos hacían compartir dentro del pasaje, con los niños; pero ahora se ha ido perdiendo eso... (Entrevista, dirigenta de la Capilla Teresita de los Andes).

El relato de los pobladores entrevistados aporta los antecedentes y características del proceso social y cultural en la construcción del territorio de la 
comunidad, lo que nos permite concluir que la memoria colectiva del barrio Tucapel Bajo está viva y presente. Sólo requiere una acción facilitadora que les permita escribir su propia historia y preservarla.

Respecto a la identificación de los fenómenos socioculturales que pudieron afectar la identidad barrial de los pobladores, el análisis de la información obtenida permite concluir que, más allá de la ausencia de un hito fundacional, el proceso de "modernización forzada" que instaló al mercado como proveedor casi exclusivo de bienes y servicios les afectó profundamente, pues la privatización de las relaciones sociales terminó debilitando su incipienteidentidad, desdibujando parte de su memoria colectiva y dañando gravemente los lazos deconfianza al interior del la comunidad.

Yo creo que la unión que había en esos años, la gente era bien unida y bien humilde. $\mathrm{Si}$ alguien tenía algún problema, la gente lo solucionaba de alguna forma. Y claro, desde eso, por ejemplo, cuando alguien fallecía, todos ayudábamos... Se mantiene, (la tradición) pero ya no tanto como antes. Se ha ido perdiendo la tradición esa de ayudarse entre todos, peroen esos años, tiene que haber sido hasta el '90... (Testimonio de un poblador).

Junto a lo anterior, la construcción de las viviendas de Villa Esperanza, meta alcanzada con el esfuerzo de toda la comunidad, sumado a la fortaleza y liderazgo de los dirigentes de la época tuvo un significado tan profundo en las familias, que ese gran esfuerzo realizado, ese logro que parecía inalcanzable, tuvo también el efecto de hacer pensar a la comunidad que no había nada más importante por hacer en el barrio, que el sueño ya estaba cumplido.

...nosotros como población, los viejos también, cuando no tenían nada, peleaban, luchaban. Ahora no, ahora tienen todo. Entonces eso es lo que cambió, el tenerlo todo significó algo que la gente cambió, como que se encerró, se fue hacia adentro. Es lo mismo que le sucede a toda la gente cuando no tiene nada y después tiene todo. No quiere saber nada de los demás, se encierra en su mundo (Testimonio de un poblador).

Los testimonios de los entrevistados, señalan que si bien estas nuevas viviendas fueron un salto cualitativo en el mejoramiento de las condiciones de vida para todas las familias, reconocen que algo ocurrió después cuando dejaron de tener esos lazos solidarios, de trabajo colectivo, voluntario y de ayuda fraterna entre los integrantes de la comunidad.

Los entrevistados externos a la comunidad, profesionales del municipio, que conocieron y acompañaron al campamento durante el proceso de construcción de las viviendas, reconocen que esta exitosa acción colectiva, por la dimensión del esfuerzo colectivo realizado, puede ser al mismo tiempo una de las causas de la actual debilidad de la organización vecinal, el escaso compromiso con el barrio y la no 
participación en actividades comunitarias como se realizaban en los años de convivencia en el antiguo campamento.

Ellos lucharon sobre eso, por eso durante muchos años y lo lograron. Yo creo que las personas como ellos, hacen un desgaste tan descomunal para lograr un objetivo de esa naturaleza, que no es fácil, yo creo que viene después por parte de ellos un relajo. Es como decir "esto es lo que queríamos, esto lo logramos, qué más quiero". Y no siguen soñando. Eso es uno, cuandologran un objetivo que lo ven como una meta inalcanzable y de repente se tan cuenta que fueron capaces y se sienten orgullosos de eso. Porque si es por historia, yo creo que tiene historia más rica que muchos otros sectores de Concepción (Testimonio del Director de Construcciones de la Municipalidad de Concepción).

Los efectos de la modernización forzada que sufrieron los sectores populares en nuestropaís durante la dictadura, es un factor que también explica el ocultamiento o debilitamiento de la memoria colectiva de los pobladores en Tucapel Bajo.

Bueno, pienso yo que la gente ahora ha cambiado mucho con las cosas que han habido últimamente. Usted sabe que la droga ha traído muchas complicaciones a las poblaciones, como que ahí ha cambiado. Antes era toda la gente unida, todos los sábados y domingos se hacían reuniones, comités del tejo, de rayuela, de fútbol. Había convivencia, ahora no, cada cual en su casa no más. Ha cambiado mucho (Testimonio de ex dirigente de la población).

Ellos reconocen que hoy prevalece la resolución individual de los problemas que enfrentan pese a que esa solución no se perciba como la más efectiva y satisfactoria. El decaimiento de la conciencia colectiva se expresa en un desencanto, falta de compromiso, interés y escepticismo respecto a la identificación de problemas comunitarios. A ello se suma una actitud dependiente respecto a la autoridad por parte de los dirigentes vecinales, lo que establece una relación paternalista, que debilita la autonomía y el respaldo de la organización poblacional.

Por otro lado, la identificación y análisis de las posibilidades de construcción patrimonial y de aspectos de la memoria histórica desde la visión de los pobladores se expresa en el reconocimiento de hechos, acontecimientos y puntos del territorio que para ellos tienen caracter simbólicos y/o especial significado para la mayoría de la comunidad. En este punto, todos los entrevistados coincidieron en señalar el momento de entrega de las viviendas, cuando se construyó Villa Esperanza, reconocieron la sede vecinal como el lugar de convivencia, de acuerdos y resolución de conflictos.

Fueron la construcción de la sede social, que fue un espacio que pudimos lograr. Siempre hubo ahí, pero con un deterioro enorme; pudimos construirla 
el 100\% nueva. Y lo otro, las áreas verdes que se recuperaron los espacios... Y la multicancha (Testimonio Expresidenta de la JJ.VV.).

Ambos hitos pueden ser patrimonializados mediante una propuesta metodológica educativa y de difusión elaborada con los propios dirigentes y líderes del barrio con el fin de rescatar su propia historia, recuperar la memoria y reforzar los elementos de identidad colectiva que vuelven a asomar con el recuerdo y el relato de estetrabajo de investigación de la comunidaddenominada Tucapel Bajo de Concepción.

Finalmente, podemos señalar que la percepción de este barrio vista desde fuera, cambia totalmente a medida que se adentra en sus vivencias cotidianas, revisa sus historias familiares, se conexta con sus recuerdos y se recogen sus testimonios. Si bien en las entrevistas aflora rapidamente el sentido de acción coletiva, este siempre es en relación a un tiempo pasado, que se remonta a los origenes del viejo campamento, donde sí reconocen acciones épicas como el trabajo de los vecinos en el relleno del humedal circundante con los residuos de un aserradero cercano para no inundarse durante los inviernos, donde a través de la convivencia posterior al trabajo voluntario se estrechaban lazos comunitarios para la construcción de un futuro colectivo. La investigación pudo establecer que efectivamente no hubo un hito fundante que diera épica al origen de la comunidad. Probablemente esto retardó o debilitó la construcción del territorio. Pero en ningún caso borró la memoria y su identidad de pobladores perteneciente al mundo de los sectores populares, pues asumen y reconocen la pobreza como desafío permanente. A lo que se agrega la carga adicional del estigma moderno de barrio peligroso.

Consideramos que este trabajo puede aportar al inicio de la recuperación del imaginario social del territorio de Tucapel Bajo que, dada su extrema marginalidad social y geográfica por su emplazamiento en la periferia urbana, ha estado por años ausente de las narrativas que contruyen la ciudad de Concepción.

\section{Bibliografía}

Aliste, E. (2009). Huellas y dinámicas territoriales: imaginarios del desarrollo y prácticas de transformación del ambiente en el Gran Concepción. Repositorio ANID. Recuperado de http://repositorio.conicyt.cl/handle/10533/203276.

Augé, M. (2000). Los no lugares. Barcelona: Editorial Gedisa.

Cárdenas, B. (2005) El barrio: de fragmentaciones e irreductibilidades. Revista LIDER, 10(14), 95-102.

Delgado, M. (2001). Lo común y lo colectivo. Recuperado de https://es.scribd.com/document/39131296/LO-COMUN-Y-LOCOLECTIVO. 
De Nordenflycht, J. (junio de 2013). El patrimonio es poder. PAT , 56, 38-43. Recuperado de https://www.patrimoniocultural.gob.cl/614/articles7011_archivo_01.pdf.

Gravano, A. (2003). Antropología de lo barrial: espacios sobre producción simbólica de la vida urbana. Buenos Aires: Espacio.

Lefebvre, H. (1974) La producción del espacio. Papers, 3, 219-229.

Lerma, E. (2013) Espacio vivido: del espacio local al reticular. Notas en torno a la representación social del espacio vivido en la globalización. Revista Pueblos y Fronteras digital, 8(15), 225-250.

Losada, F. (2001) El espacio vivido: una aproximación semiótica. Cuadernos de la Facultad de Humanidades y Ciencias Sociales, 17, 271-294.

Memoria Chilena (s.f.). Migración campo-ciudad (1885-1952). Recuperado de http://www.memoriachilena.gob.cl/602/w3-article-750.html.

Saldía, C. (2018). Relatos visuales en torno a la memoria del barrio Aurora de Chile como un ejercicio de resistencia ciudadana en Concepción. Tesis para optar al grado de Magíster en Arte y Patrimonio por la Universidad de Concepción.

La citas de testimonios corresponden a entrevistas realizadas entre el 30 de septiembre de 2018 y el 12 de abril de 2019:

(1) Testimonio Ex dirigente de la JJ.VV de Tucapel Bajo

(2) Testimonio Ex Presidente de la JJ VV de Tucapel Bajo

(3) Testimonio ex presidenta de la JJ.VV de Villa Esperanza

(4) Testimosnio de Asistente social de la Municipalidad de Concepción

(5) Testimonio de Director de Construcciones de la Municipalidad de Concepción

(6) Testimonio poblador

(7) Testimonio coordinadora Grupo Católico Capilla Teresita de los Andes 